\title{
An analysis of inter-healthcare facility transfer of neonates within the eThekwini Health District of KwaZulu-Natal, South Africa
}

\author{
P Ashokcoomar, ${ }^{1,2}$ MTech Emergency Medical Care; R Naidoo, ${ }^{1}$ MSc (Cardiol), MSc (Med) \\ ${ }^{1}$ Department of Emergency Medical Care and Rescue, Durban University of Technology, South Africa \\ ${ }^{2}$ KwaZulu-Natal Emergency Medical Services, Durban, South Africa
}

Corresponding author: P Ashokcoomar (pradeep.ashokcoomar@gmail.com)

\begin{abstract}
Objectives. To investigate delays in the transfer of neonates between healthcare facilities and to detect any adverse events encountered during neonatal transfer.

Methods. A prospective study was conducted from December 2011 to January 2012. A quantitative, non-experimental design was used to undertake a descriptive analysis of 120 inter-healthcare facility transfers of neonates within the eThekwini Health District (Durban) of KwaZulu-Natal Province, South Africa. Data collection was via questionnaire. Data collection was restricted to the Emergency Medical Services (EMSs) of eThekwini Health District, which is the local public ambulance provider.

Results. All transfers were undertaken by road ambulances: $83(62.2 \%)$ by frontline ambulances; 35 (29.2\%) by the obstetric unit; and $2(1.7 \%)$ by the planned patient transport vehicles. Twenty-nine (24.2\%) transfers involved critically ill neonates. The mean (standard deviation (SD)) time to complete an inter-healthcare facility transfer was $3 \mathrm{~h} 49 \mathrm{~min}(1 \mathrm{~h} 57 \mathrm{~min}$ ) (range $0 \mathrm{~h} 55 \mathrm{~min}-10 \mathrm{~h} 34 \mathrm{~min}$ ). Problems with transfer equipment were common due to poor resource allocation, malfunctioning equipment, inappropriate equipment for the type of transfer and dirty or unsterile equipment. The study identified $10(8.3 \%)$ physiologically related adverse events, which included $1(0.8 \%)$ death plus a further $18(15.0 \%)$ equipment-related adverse events. Conclusions. EMS is involved in transporting a significant number of intensive care and non-intensive care neonates between healthcare facilities. This study has identified numerous factors affecting the efficiency of inter-facility transfer of neonates and highlights a number of areas requiring improvement.
\end{abstract}

S Afr Med J 2016;106(5):514-518. DOI:10.7196/SAMJ.2016v106i5.8554

The inter-healthcare transfer of neonates is an integral component of neonatal care and is often driven by a lack of local neonatal cots or the need for specialist intervention. Inter-healthcare transfer can result in clinical deterioration, which impacts directly on neonatal morbidity and mortality. ${ }^{[1]}$ To maintain the continuum of care, neonatal transfer requires careful planning, skilled personnel and specialised equipment. One of the main focus areas of the World Health Organization's Millennium Development Goal 4 is maternal and child health, yet in sub-Saharan Africa, infant mortality remains high, with one child in every eight dying before their 5th birthday (129 per 1000 live births). South Africa (SA) set a target to reduce infant and child mortality rate to 20 deaths per 1000 live births by $2015{ }^{[2,3]}$ These initiatives are, however, largely focused on improving hospital and clinic facilities as opposed to emergency medical services (EMSs). ${ }^{[3]}$ The EMS in the eThekwini Health District of KwaZulu-Natal (KZN) Province is the provincial ambulance service providing prehospital care and inter-hospital transfer for $\sim 3.5$ million people in a geographical area of over of $2291 \mathrm{~km}^{2} \cdot{ }^{[4]}$ All referrals are co-ordinated via a central EMS communication centre dispatching both road and aeromedical ambulance services. Ambulances are staffed by emergency care providers registered with the Health Professions Council of South Africa as basic ambulance assistants (BAAs), ambulance emergency assistants (AEAs), paramedics, emergency care technicians (ECTs) or emergency care practitioners (ECPs) (Table 1).

Inter-healthcare transfers are provided through either the planned patient transport (PPT) or emergency response divisions of EMS. PPT service provides an elective patient transport service and interhealthcare facility transfers operating weekdays from $08 \mathrm{~h} 00-16 \mathrm{~h} 00$.
Currently there is no specialist neonatal transfer team allocated for neonatal inter-healthcare facility transport and EMS provide this service either by the emergency response or the PPT service depending on clinical need and time of the day the request is made. Neonatal transport equipment is placed in various ambulance bases and in the event of neonatal transfer, the ambulance crew collects the equipment before reporting to the requesting hospital. High-risk neonatal transfers such as intubated neonates are escorted by paramedics. All paramedics receive specific training in neonatal inter-hospital transfer. Currently there is limited research associated with the transfer process within SA, particularly with regards to how it is provided.

\section{Methods}

A quantitative, non-experimental design was used to undertake a descriptive analysis of 120 inter-healthcare facility transfers of neonates (from birth to the first 28 days of life) within the eThekwini Health District. Data were collected prospectively from 19 December 2011 to 30 January 2012. Only the public sector ambulance service of the eThekwini Health District was included in the study.

Data were obtained from two questionnaires: the first was completed by communications officers at the communication centre, and the second by the most senior emergency care provider of each transfer team. The service of a professional statistician was used to analyse raw data. The computer software programs used were SPSS Statistics version 20.0 (IBM, USA) and Statgraphics Centurion 15.1 (Statgraphics, USA). The statistical aspect of the research encompassed descriptive statistics, inferential statistics and the $\chi^{2}$ test. For logistical reasons, the study was limited to one health district, instead of the entire province of KZN. Furthermore, the 
study did not include private sector EMS, who also undertake interfacility neonatal transfers.

Ethical approval was granted by the Institutional Research Ethics Committee (IREC) of the Durban University of Technology (Ethics Clearance No.: IREC 001/11)

\section{Results}

All inter-healthcare facility transfers $(n=120)$ were undertaken by road ambulances, with emergency ambulances undertaking 83 (69.0\%) transfers, an obstetric ambulance undertaking 35 (29.0\%) transfers and the planned patient transport units undertaking 2 (2\%) transfers. Ninety-three (77.5\%) neonates were referred from hospitals and $27(22.5 \%)$ were referred from primary healthcare clinics.

Sixty-nine $(57.5 \%)$ cases were primary transfers for specialised or higher level of care while the remaining cases $51(42.5 \%)$ were return transfers (Table 2). A total of $92(76.7 \%)$ of the neonates were preterm, $26(21.7 \%)$ were term and $2(1.7 \%)$ were post term (Table 3). The mean (standard deviation (SD)) time to complete an inter-healthcare facility transfer was $3 \mathrm{~h} 49 \mathrm{~min}$ (1 h $57 \mathrm{~min})$ (range $0 \mathrm{~h} 55 \mathrm{~min}-10 \mathrm{~h} 34 \mathrm{~min}$ ) (Table 4). There were delays in dispatch (>3 min) (Fig. 1) due to ambulance non-availability in $70(47.3 \%)$ instances, no paramedic was available for $48(32.4 \%)$ transfers where a paramedic was deemed to be required, no AEA personnel were available to support the neonatal transfer on 7 (4.7\%) occasions and on $23(15.5 \%)$ occasions, neonatal transfer equipment was not available. Seventeen (14.2\%) requests for the inter-healthcare facility transfer of neonates did not require any specialist equipment. Paramedics were dispatched to $6(35.3 \%)$ transfers, ECTs to $2(11.8 \%)$, AEAs to $3(17.6 \%)$ and BAAs to 6 (35.3\%). Delays were common in a number of instances, and the reasons for these delays were numerous. Forty-eight (32.4\%) of the transfers were delayed due to no paramedics being available. However, paramedics were only required in $29(60.4 \%)$ of the 48 transfers. The control centre is staffed by either BAAs or AEAs. Improved information gathering by the ambulance control centre from the referring hospital may minimise transfer delay (Table 5).

There were $10(8.3 \%)$ physiologically related adverse events during transfer, including one death. The remaining nine incidents were all potentially life threatening. Thirteen neonates (10.8\%) required clinical intervention during transportation and 8 (6.7\%) intervention on arrival at the receiving hospital (Table 6). There is a significant relationship between pretransport intervention performed and mean

\section{Table 1. Prehospital emergency care categories of registration} with HPCSA

\begin{tabular}{ll}
\hline Qualification* & Description \\
\hline BAA & $\begin{array}{l}\text { An entry-level, 4-week qualification leading to a } \\
\text { basic life support scope of practice }\end{array}$ \\
AEA & $\begin{array}{l}\text { A mid-level 4-month qualification leading to an } \\
\text { intermediate life support scope of practice of a } \\
\text { limited number of invasive techniques }\end{array}$ \\
Paramedic & $\begin{array}{l}\text { This is either a 1-year or a 3-year qualification } \\
\text { leading to an ALS scope of practice of an array of } \\
\text { invasive techniques }\end{array}$ \\
ECT & $\begin{array}{l}\text { A 2-year mid-level qualification leading to a limited } \\
\text { number of skills within the ALS scope of practice }\end{array}$ \\
ECP & $\begin{array}{l}\text { ALS } 4 \text {-year professional Bachelor degree within the } \\
\text { practice which includes thrombolysis and rapid } \\
\text { sequence intubation }\end{array}$ \\
$*$ All qualifications are registered with the HPCSA.
\end{tabular}

time delay at the referring hospital $(p=0.018)$. Fifteen $(12.5 \%)$ neonates were inappropriately prepared for transport by the referral hospital, resulting in delays in the transfer. Six (5.0\%) neonates were deemed to be too unstable for transfer, with paramedics having been dispatched to $5(83.3 \%)$, and $1(16.7 \%)$ to AEAs.

In $18(15.0 \%)$ transfers there were adverse events associated with equipment failure and issues with equipment being unavailable (Table 7). Correlation between paramedic transfers undertaken and equipment-related adverse events shows that 18 (15.0\%) transfers experienced adverse events, of which 11 (61.1\%) occurred during paramedic transfer. Correlation between physiologically related adverse events and equipment-related adverse events shows that 5

Table 2. Referring and receiving facilities, primary and return transfers and dayshift and nightshift transfers

$n(\%)$

Referring facilities

Prince Mshiyeni Memorial Hospital

$9(7.5)$

R K Khan Hospital

St Mary's Hospital

King Edward VIII Hospital

Mahatma Gandhi Memorial Hospital

Addington Hospital

Inkosi Albert Luthuli Central Hospital

Clairwood Hospital

St Augustine's Hospital

Isipingo Medical Towers Hospital

Wentworth Hospital

City Health Hospital

Primary Health Clinic

Total

Receiving facilities

Prince Mshiyeni Memorial Hospital

R K Khan Hospital

St Mary's Hospital

King Edward VIII Hospital

Mahatma Gandhi Memorial Hospital

Addington Hospital

Inkosi Albert Luthuli Central Hospital

Clairwood Hospital

St Augustine's Hospital

Isipingo Medical Towers Hospital

Osindisweni Hospital

Cancelled

Total

Primary and return transfers

Primary transfers

Return transfers

Total

Dayshift and nightshift transfers

Dayshift

Nightshift

Total

$120(100)$ 
(50.0\%) of the $10(8.3 \%)$ physiologically related adverse events that occurred during transfers were a direct result of equipmentrelated adverse events. Although a small number was involved $(5(50.0 \%))$, the $\chi^{2}$ test showed a statistically significant $p$-value of 0.007 .

\section{Discussion}

There were 120 neonatal transfers in 43 days (average 2.79 per day). This is a high incidence compared with Ireland $^{[5]}$ or Slovenia, ${ }^{[6]}$ where between 0.482 and 0.487 inter-facility transfers take place per day, respectively. The higher incidence of transfers in the eThekwini Health District can be attributed to a lack of specialised neonatal facilities and trained staff.

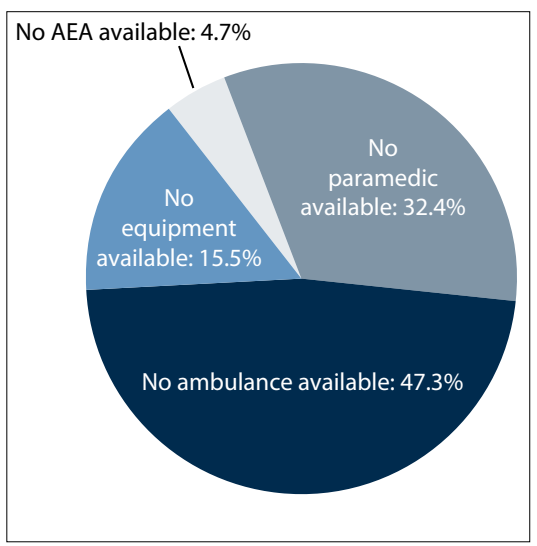

Fig. 1. Reasons for delay in dispatch.

\begin{tabular}{|c|c|c|c|}
\hline Variable & $n(\%)$ & Variable & $n(\%)$ \\
\hline Neonatal age & & Diagnosis & \\
\hline From birth to 4 hours & $11(9.2)$ & Preterm & $90(75.0)$ \\
\hline Between 4 hours and 1 day & $21(17.5)$ & Respiratory distress syndrome & $49(40.8)$ \\
\hline Between 1 day and 7 days & $35(29.2)$ & Meconium aspiration syndrome & $13(10.8)$ \\
\hline Between 7 days and 28 days & $53(44.2)$ & Hyaline membrane disease & $24(20.0)$ \\
\hline Total & $120(100)$ & Low birth weight & $25(20.8)$ \\
\hline Neonatal weight (g) & & Neonatal sepsis & $6(5.0)$ \\
\hline$<1000$ & $6(5.0)$ & Supportive care & $2(1.7)$ \\
\hline $1000-1499$ & $42(35.0)$ & Apnoea & $2(1.7)$ \\
\hline $1500-1999$ & $29(24.2)$ & Infection or suspected infections & $14(11.7)$ \\
\hline $2000-3999$ & $38(31.7)$ & Patent ductus arteriosus & $4(3.3)$ \\
\hline$>4000$ & $5(4.2)$ & Retinopathy of prematurity & $1(0.8)$ \\
\hline Total & $120(100)$ & Tricuspid atresia & $1(0.8)$ \\
\hline Neonatal sex & & Pyloric stenosis & $1(0.8)$ \\
\hline Male & $83(69.2)$ & Perforated trachea & $1(0.8)$ \\
\hline Female & $37(30.8)$ & Birth abnormalities & $3(2.5)$ \\
\hline Total & $120(100)$ & Tumour to eye & $5(4.2)$ \\
\hline Gestational age & & Congenital heart disease & $2(1.7)$ \\
\hline Preterm & $92(76.7)$ & Congenital pneumonia & $12(10.0)$ \\
\hline Term & $26(21.7)$ & Exposed intestines & $2(1.7)$ \\
\hline Post-term & $2(1.7)$ & Abdominal obstruction & $5(5.2)$ \\
\hline \multirow[t]{3}{*}{ Total } & $120(100)$ & Perforated bowel & $1(0.8)$ \\
\hline & & Hydrocephalus & $2(1.7)$ \\
\hline & & Diaphragmatic hernia & $3(2.5)$ \\
\hline
\end{tabular}

Table 4. Timeframes for the inter-healthcare transfers

\begin{tabular}{|c|c|c|c|c|c|}
\hline & Time difference & Min. (h:min) & Max. (h:min) & Mean (SD) (h:min) & 95\% (CI) (h:min) \\
\hline From request (T1) to dispatch (T2) & $\mathrm{T} 2-\mathrm{T} 1$ & 00:04 & 07:50 & $01: 20(01: 36)$ & 01:04 - 01:39 \\
\hline $\begin{array}{l}\text { From dispatch to becoming mobile to the } \\
\text { referring hospital (T3) }\end{array}$ & T3 - T2 & 00:00 & 04:00 & $00: 27(00: 44)$ & $00: 20-00: 36$ \\
\hline $\begin{array}{l}\text { From time of becoming mobile to the referring } \\
\text { hospital to time at the referring hospital (T4) }\end{array}$ & $\mathrm{T} 4-\mathrm{T} 3$ & 00:00 & 03:42 & $00: 21(00: 24)$ & $00: 17-00: 26$ \\
\hline $\begin{array}{l}\text { From time at the referring hospital to time of } \\
\text { becoming mobile to the receiving hospital (T5) }\end{array}$ & $\mathrm{T} 5-\mathrm{T} 4$ & 00:00 & 02:17 & $00: 43(00: 26)$ & $00: 39-00: 49$ \\
\hline $\begin{array}{l}\text { From time of becoming mobile to receiving } \\
\text { hospital to the time at receiving hospital (T6) }\end{array}$ & T6 - T5 & 00:00 & 01:30 & $00: 27(00: 16)$ & $00: 24-00: 30$ \\
\hline $\begin{array}{l}\text { From time at receiving hospital to time of } \\
\text { completion at receiving hospital (T7) }\end{array}$ & T7 - T6 & 00:01 & 01:50 & $00: 28(00: 14)$ & $00: 25-00: 31$ \\
\hline Total time taken to complete transfer & $\mathrm{T} 7-\mathrm{T} 1$ & $00: 55$ & $10: 34$ & $03: 49(01: 57)$ & $03: 29-04: 12$ \\
\hline
\end{tabular}

Table 5. Qualification and experience of telephone operator

\begin{tabular}{lllll}
\hline Qualification of telephone operator & $\boldsymbol{n}(\%)$ & Time (years) & Communication experience, $\boldsymbol{n}(\%)$ & Operational experience, $\boldsymbol{n}(\%)$ \\
\hline BAA & $71(59.2)$ & None & - & $33(27.5)$ \\
AEA & $49(40.8)$ & $<1$ & $36(30.0)$ & $2(1.7)$ \\
Paramedic & - & $1-3$ & $3(2.5)$ & $5(4.2)$ \\
ECT & - & $3-5$ & $3(2.5)$ & $2(1.7)$ \\
ECP & - & $>5$ & $78(65.0)$ & $78(65.0)$ \\
Total & $120(100)$ & Total & $120(100)$ & $120(100)$
\end{tabular}


Table 6. Skill intervention performed

\begin{tabular}{|c|c|c|c|c|c|}
\hline Intervention pretransport & $n(\%)$ & Intervention during transport & $n(\%)$ & $\begin{array}{l}\text { Intervention post } \\
\text { transport }\end{array}$ & $n(\%)$ \\
\hline Oxygenation via BVM & $13(10.8)$ & Oxygenation via BVM & $9(7.5)$ & Oxygenation via BVM & $6(5.0)$ \\
\hline Suctioning & $2(1.7)$ & Suctioning & $4(3.3)$ & Suctioning & $1(0.8)$ \\
\hline Admin. of pharm. agents & $6(5.0)$ & Admin. of pharm. agents & $3(2.5)$ & Admin. of pharm. agents & $2(1.7)$ \\
\hline Intubation & $2(1.7)$ & Admin.of fluids & $3(2.5)$ & & \\
\hline Adjusting depth of tracheal tube & $2(1.7)$ & Intravenous cannulation & $1(0.8)$ & & \\
\hline Restrapping tracheal tube & $3(2.5)$ & Cardiopulmonary resuscitation & $1(0.8)$ & & \\
\hline NGT insertion & $1(0.8)$ & & & & \\
\hline Admin. of fluids & $1(0.8)$ & & & & \\
\hline
\end{tabular}

\section{Table 7. Equipment required before proceeding with the transfer}

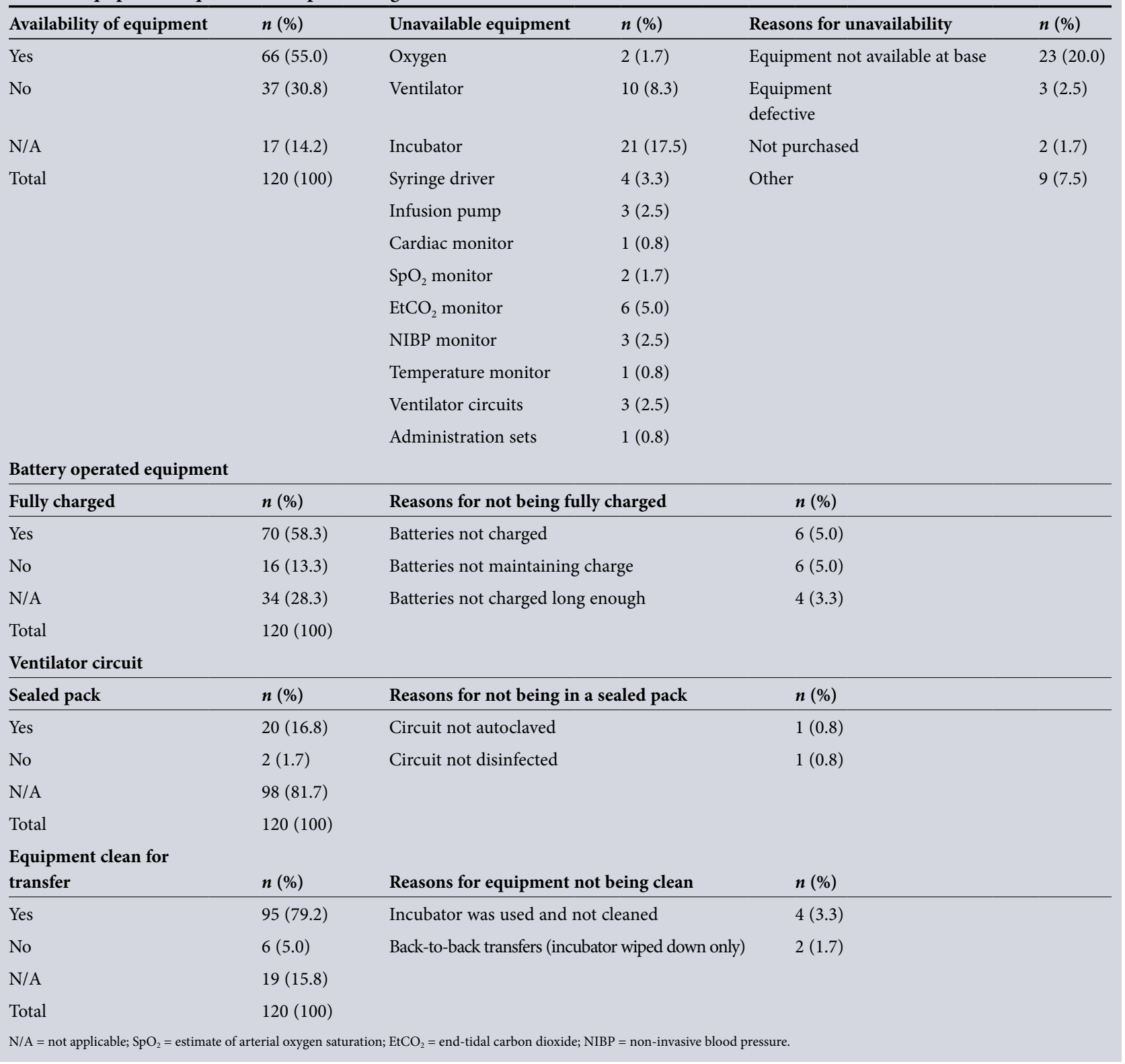

Caring for a critically ill neonate during a transfer is very different to caring for a neonate in a neonatal intensive care unit. This is because EMS personnel have to deal with adverse weather conditions, noise, mechanical vibration, unstable equipment, restricted lighting, limited work space and limited support services. However, with appropriate equipment and appropriate utilisation of staff with specialist training, 
inter-facility neonatal transfers can be safely undertaken. ${ }^{[7]}$ There is rarely a need for haste when undertaking a neonatal intensive care transfer. The speed of the actual transfer is no substitute for the time invested in resuscitating and stabilising the neonate before transfer. Taking intensive care to the neonate and pretransport stabilisation may be more beneficial than rapid delivery to a healthcare facility. ${ }^{[8]}$

EMS in the eThekwini Health District has no specialised or dedicated transport team for neonatal inter-health care facility transfer. Studies highlighted equipment and physiologically related adverse events and time delays in the transportation of neonates when these transfers are carried out by non-specialised neonatal transportation teams. ${ }^{[5,6,10]}$ This study demonstrated similar results. The introduction of dedicated or skilled regional teams with dedicated ambulances may help minimise intra-transfer deterioration. Inexperienced and junior staff in the communication centre also contributed towards delays, as evidenced by the dispatch of inappropriate neonatal transfer equipment and the inadequate dispatch of emergency care personnel. All physiologically related adverse events were life-threatening, with conditions such as respiratory and cardiac deterioration, desaturation, development of hypothermia and cardiorespiratory arrest. One death occurred during neonatal transfer. The cause of the neonatal death was multifaceted: reasons included inappropriate pretransport preparation, lack of pretransfer stabilisation and a lack of available Advanced Life Support (ALS) personnel, which resulted in clinical supervision being delegated to a less-qualified ambulance clinician. It is feasible that the appropriate allocation of a paramedic to this transfer may have prevented the adverse outcome.

\section{Conclusion}

This study identified numerous shortfalls in inter-healthcare facility transfer of neonates, with the greatest shortcomings being time delays, equipment problems and adverse events. Clear protocols and programmes are to be developed in resource-constrained environments to address the problems identified in the study. Specialised and dedicated transport teams with a thorough understanding of the transfer process, that utilise sophisticated transportation equipment and well-structured processes are required for the safe and expedient inter-healthcare transfer of neonates. To achieve a high standard of neonatal care and monitoring (both on the ground and in the air), it is essential that there is effective communication and co-ordination between all role players, as well as meticulous stabilisation and training programmes. This must be underpinned by good team work by all role players. Only then can the transport service achieve clinical excellence.

Acknowledgements. The authors would like to express appreciation to Prof. J K Adam for the technical assistance provided, and Dr R Maharaj for his guidance and input.

\section{References}

1. Messner H. Neonatal transport: A review of the current evidence. Early Hum Dev 2011;87(Suppl 1):77. DOI:10.1016/j.earlhumdev.2011.01.018

2. United Nations. Millennium Development Goals, 2011. http://www.undp.org/mdg (accessed 15 March 2011).

3. De Vries S, Wallis LA, Maritz D. A retrospective evaluation of the impact of a dedicated obstetric and De Vries S, Wallis LA, Maritz D. A retrospective evaluation of the impact of a dedicated obstetric and
neonatal transport service on transport times within an urban setting. Int J Emerg Med 2011;4(1):28 neonatal transport service on transport times within an urban setting. Int J Emerg Med 2011;4(1):28
DOI:10.1186/1865-1380-4-28 DOI:10.1186/1865-1380-4-28

4. South African Cities Network. eThekwini Municipality. 2010. www.sacities.net (accessed 22 May 2010

5. Mullane D, Byrne H, Clarke TA, et al. Neonatal transportation: The effects of neonatal transportation programme. Ir J Med Sci 2004;173(2):105-108.

6. Grosek S. Air and Ground Transport of Critically Ill Neonates and Infants in Slovenia. Ljubljana: Department for Pediatric Surgery and Intensive Care, University Medical Center, 2007:88-91.

Boxwell G. Neonatal Intensive Care Nursing. 2nd ed. New York: Routledge, 2010.

8. Stroud HM, Prodhan P, Moss M, Fiser R, Schexnayder S, Anand K. Enhanced monitoring improves pediatric transport outcomes: A randomized controlled trial. Pediatrics 2011;127(1):42-48. DOI:10.1542/peds.2010-1336

9. Britto J, Nadel S, Maconochie I, Levin M, Habibi P. Morbidity and severity of illness during interhospital transfer: Impact of a specialised paediatric retrieval team. BMJ 1995;311(7009):836-839.

Accepted 3 March 2016. 